\title{
MEDIA PEMBELAJARAN KONSERVASI DAN EFISIENSI ENERGI PADA MATA KULIAH KONSTRUKSI BANGUNAN GEDUNG Mochamad Sahrul Aripin ${ }^{1)}$, Anis Rahmawati' ${ }^{2)}$, Taufiq Lilo Adi Sucipto ${ }^{3)}$ sahrularipin@gmail.com
}

\begin{abstract}
ABSTRAK
Penelitian ini bertujan sebagai alat bantu pembelajaran konstruksi bangunan gedung. Luaran dari penelitian adalah desain konservasi dan efisiensi energi pada rumah ramah lingkungan yang diwujudkan berupa maket, buku pegangan maket dan Rencana Pelaksanaan Pembelajaran (RPP).

Penelitian ini termasuk penelitian bersifat deskriptif menggunakan metode research and development (R\&D). Model pengembangan yang digunakan dalam penelitian ini adalah model deskriptif pada level satu yang menunjukkan langkah-langkah yang harus diikuti antaralain: potensi dan masalah; studi literatur dan pengumpulan informasi; desain produk; validasi desain dan desain teruji. Validasi dalam penelitian ini dilakukan oleh ahli materi, ahli pembelajaran dan ahli media.

Berdasarkan hasil penelitian diperoleh Hasil validasi oleh ahli materi pada aspek kelayakan isi atau materi, media yang telah dibuat termasuk dalam kriteria sangat baik. Hasil validasi oleh ahli pembelajaran pada aspek kelayakan Rencana Pelaksanaan Pembelajaran (RPP), media pembelajaran yang telah dibuat termasuk dalam kriteria sangat baik. Hasil validasi oleh ahli media pada aspek kelayakan media, media yang telah dibuat termasuk dalam kriteria sangat baik. Produk yang dihasilkan berupa maket, buku pegangan dan Rencana Pelaksanaan Pembelajaran (RPP) sebagai pedoman penggunaan media dalam pembelajaran. Berdasarkan analisis data dan pembahasan dapat disimpulkan bahwa produk desain konservasi dan efisiensi energi pada rumah ramah lingkungan baik untuk dimanfaatkan sebagai media pembelajaran konstruksi bangunan gedung.
\end{abstract}

Kata kunci: konservasi, efisiensi, energi, media

\footnotetext{
1) Mahasiswa Program Studi Pendidikan Teknik Bangunan FKIP UNS

2) Pengajar Program Studi Pendidikan Teknik Bangunan FKIP UNS

3) Pengajar Program Studi Pendidikan Teknik Bangunan FKIP UNS
} 


\title{
INSTRUCTIONAL MEDIA OF ENERGY CONSERVATION AND EFFICIENCY ON CONSTRUCTION BUILDING COURSE Mochamad Sahrul Aripin ${ }^{1)}$, Anis Rahmawati' ${ }^{2)}$, Taufiq Lilo Adi Sucipto ${ }^{3)}$ \\ sahrularipin@gmail.com
}

\begin{abstract}
The purpose of this research is as a learning aid for building construction. The output of the research is the design of conservation and energy efficiency in environmentally friendly house which is realized in the form of maket, manual handbooks and Learning Implementation Plan (RPP).

This research includes descriptive research using research and development (R\&D) method. The development model used in this research is a descriptive model at level one which shows the steps to be followed among other: potential and problems; study of literature and information gathering; product design; validation of design and design tested. Validation in this study was conducted by material experts, learning experts and media experts.

Based on the research results obtained validation results by the material experts on the content feasibility aspects or materials, media that have been made included in the criteria very well. The results of validation by the learning expert on the feasibility aspects of the Learning Implementation Plan (RPP), the learning media that has been made included in the criteria is very good. The results of validation by media experts on media feasibility aspects, media that have been made included in the criteria very well. The resulting product is a maket, handbook and Learning Implementation Plan (RPP) as a guide for media use in learning. Based on data analysis and discussion it can be concluded that the design product of conservation and energy efficiency in environmentally friendly house is good to be utilized as education media of construction building course.
\end{abstract}

Keywords: Conservation, efficiency, energy, media

1) Mahasiswa Program Studi Pendidikan Teknik Bangunan FKIP UNS

2) Pengajar Program Studi Pendidikan Teknik Bangunan FKIP UNS

3) Pengajar Program Studi Pendidikan Teknik Bangunan FKIP UNS 


\section{PENDAHULUAN}

Fenomena pemanasan global telah menjadi pembahasan yang sangat penting dan serius beberapa tahun terakhir, bukan saja dikalangan pemerintah, negara-negara di forum internasional, melainkan juga dikalangan aktivis lingkungan dan bahkan, berita mengenai efek dari pemanasan global selalu menjadi perbincangan yang hangat di berbagai media serta kalangan masyarakat. Perubahan iklim merupakan kelanjutan dari pemanasan global. Gas karbon dioksida maupun gas-gas rumah kaca yang naik ke atmosfer secara berlebihan tersebut kemudian akan menyebabkan akumulasi panas yang berlebihan, sehingga iklim akan melakukan penyesuaian terkait peningkatan temperatur bumi dan akan merubah iklim regional, seperti: pola curah hujan, penguapan, dan pembentukan awan.

Konsumsi energi listrik di Indonesia setiap tahun mengalami peningkatan seiring dengan bertambahnya jumlah penduduk, meningkatnya kemampuan ekonomi masyarakat, dan pesatnya perkembangan teknologi. Berdasarkan data statistik PLN, penjualan listrik pada tahun 2012 meningkat hingga $173 \%$ dari penjualan listrik pada tahun 2004. Penyediaan energi listrik PLN yang masih didominasi oleh bahan bakar fosil menunjukkan bahwa lstrik PLN masih terbatas, sehingga perlu dilakukan penghematan dalam pemanfaatannya.

Persentase konsumsi energi di sektor komersial dan bangunan hanya berkisar $4 \%$ dari keseluruhan konsumsi energi nasional. Diketahui pada sektor insutri $39,49 \%$, sektor transportasi $32,2 \%$, penggunaan non-energi $10,59 \%$, rumah tangga $10,2 \%$, dan lain-lain $3,4 \%$. Pertumbuhan konsumsi energi dalam 20 tahun terakhir pada sektor komersial dan bangunan mencapai persentase tertinggi pada $8,58 \%$, dengan rincian pada sektor industri $5,1 \%$, transportasi $6,4 \%$, penggunaan nonenergi $5,4 \%$, rumah tangga $3,1 \%$, dan lain-lain 0,03\% (Pedoman Efisiensi Energi, 2005: 5).

Kebutuhan energi listrik pada sektor bangunan gedung perkantoran membutuhkan energi listrik hingga $201-285 \mathrm{kWh} / \mathrm{m}^{2}$ setiap tahunnya (Peraturan Gubernur DKI Nomor 38 Tahun 2012 tentang Bangunan Gedung Hijau). Pada tahun 2011 bahwa sektor bangunan membutuhkan hingga 50\% total pengeluaran energi di Indonesia serta menghasilkan emisi Gas Rumah Kaca (GRK) hingga 30\%. Bahkan anggaran belanja negara tersedot sangat banyak pada sektor listrik dan BBM pada ABN-P 2013 dengan nilai mencapai 299,8 triliun rupiah dan masih menganggarkan lagi sebesar 282,1 triliun rupiah untuk APBN 2014 (sumber: Litbang Kompas/Kompas 27 Oktober 2013) dalam (Anwar Subkiman, 2014: 1). 
Kegiatan manusia hampir sepenuhnya berada didalam rumah, lebih dari 14 jam manusia berada dirumah untuk menghabiskan waktu. Berdasarkan survey konsumsi energi di Perumnas Bandung tahun 2009 diperoleh hasil antaralain: $20 \%$ untuk pencahyaan, $60 \%$ untuk peralatan elektronik (kulkas, rice cooker, televisi, komputer, mesin cuci dan lain-lain) dan $20 \%$ untuk penghawaan (Kipas angin, AC dan lain-lain) (Wonohardjo, 2009: 7).

Hal ini tentunya menimbulkan banyak pengaruh, seperti yang diungkapkan Ashie (dalam Wonohardjo, 2009: 12) bahwa pengaruh buruk pada lingkungan luar yang diakibatkan oleh berlebihnya konsumsi energi pada rumah, sebagai berikut: terjadi fenomena panas pada bumi, peningkatan kebutuhan pada ruang, penurunan kinerja AC dan peningkatan pelepasan panas buatan.

Konservasi dan efisiensi energi pada rumah tinggal telah diatur oleh Green Building Council Indonesia (GBCI). Namun, dalam pengaplikasiannya belum adanya Grand Design yang sesuai dengan konsep GBCI. Konsep yang dikeluarkan GBCI dalam urusan konservasi dan efisiensi energi mencakup delapan aspek, yaitu: penggunaan meteran listrik, analisis desain pasif, sub meteran, pencahayaan buatan, pengkondisian udara, reduksi panas, penggunaan piranti rumah tangga hemat energi, dan sumber energi terbaharukan.
Oleh karenanya dibutuhkan suatu upaya yang dapat mengurangi penggunaan energi berlebih. Dengan penerapan konsep rumah ramah lingkungan diharapkan dapat mengurangi penggunaan energi berlebih dan meminimalisir dampak buruk yang ditimbulkan dari penggunaan energi berlebih. Dengan adanya konsep rumah ramah lingkungan akan menimbulkan rumah efisien energi dimana bijak dalam menggunakan energi sebagai kebutuhannya.

Hasil penelitian yang dilakukan oleh Jeni Pujiastuti (2013) juga mendukung pentingnya konservasi dan efiesiensi energi pada gedung. Hasil penelitian tersebut menunjukkan bahwa latar belakang pembangunan gedung kantor Bank Indonesia Solo adalah untuk efisiensi energi dan membuat bangunan ramah lingkungan yang berdampak positif bagi lingkungan, ekonomi, dan sosial.

Sosialisasi yang dapat dilakukan dalam mewujudkan rumah efisien energi salah satunya adalah dengan menerapkan pembelajaran ramah lingkungan pada kurikulum satuan pendidikan tinggi. Tujuannya adalah upaya pelestarian alam yang dapat dilakukan dan ditularkan sehingga menciptakan sebuah kolaborasi dimana calon guru dibekali ilmu selanjutnya ketika sudah menjadi guru ilmunya diberikan kepada muridnya, lalu muridnya menerapkannya. Keadaan ini tentu akan mendukung upaya 
konservasi dan efisiensi energi dari sektor pendidikan, sehingga kebutuhan energi bisa ditekan dan menimbulkan keseimbangan alam dan manusia. Salah satu upaya yang dapat dilakukan dalam dunia pendidikan adalah dengan menggunakan media pembelajaran sebagai sarana mahasiswa untuk mempermudah pemahaman konsep ramah lingkungan.

Menurut Brown dalam Indriana. D (2011: 15) mengatakan bahwa media pembelajaran adalah media yang digunakan dengan baik oleh guru atau siswa dapat mempengaruhi efektivitas program belajarmengajar. Dalam pengertian ini media diartikan sebagai fasilitas komunikasi, yang dapat memperjelas makna antara komunikator dan komunikan.

Media yang digunakan dalam pembelajaran beraneka ragam, diantaranya buku teks, modul, overhead transparansi, film, video, slide, komik, kokami, fotonovela, dan maket. Maket menurut Sudjana dan Rivai dalam Prasotowo (2010: 227) mengungkapkan bahwa maket adalah tiruan tiga dimensi dari beberapa benda nyata yang terlalu besar, terlalu jauh, terlalu jarang atau terlalu ruwet untuk dibawa kedalam kelas dan dipelajari peserta didik dalam wujud aslinya. Dalam mendukung maket sebagai media pembelajaran diperlukan sesuatu yang membantu maket dalam memperjelas isi materi yang terkandung dalam maket salah satunya dengan booklet.

Menurut Roymond S. Simamora (2009: 71), booklet adalah buku berukuran kecil (setengah kuarto) dan tipis, tidak lebih dari 30 lembar bolak balik yang berisi tentang tulisan dan gambar- gambar. Selain itu, pendapat lain menurut Heri D.J Maulana (2009: 174) booklet merupakan media untuk menyampaikan pesan-pesan dalam bentuk buku, baik berupa tulisan maupun gambar.

Media memiliki arti penting untuk keberhasilan sebuah pembelajaran. Media merupakan segala sesuatu yang dapat digunakan untuk menyalurkan pesan dari pengirim pesan kepada penerima pesan, sehingga dapat merangsang pikiran dan perasaan. Hal itu ditegaskan juga oleh Park (2001: 18) yang menyampaikan, bahwa dengan media peserta didik mengkonstruksi sendiri pengetahuan dan pemahaman mereka, guru tidak bias mengirimkan ide ke pelajar yang pasif. Ide-ide ini merupakan alat yang dapat digunakan untuk mengkonstruksi konsep dan prosedur baru. Ide-ide ini tidak dapat dituangkan ke diri anak sebagaimana menuangkan air ke bejana kosong.

\section{METODE PENELITIAN}

Penelitian ini menggunakan pendekatan penelitian dan pengembangan (Research and Development) sedangkan model yang dipilih 
adalah model penelitian dan pengembangan pendidikan yang dikembangkan oleh Sugiyono (2016: 297) yang menjelaskan bahwa metode penelitian dan pengembangan adalah metode penelitian yang digunakan untuk menghasilkan produk tertentu, dan menguji keefektifan produk tersebut yang ditempuh melalui langkah-langkah yang harus dilakukan

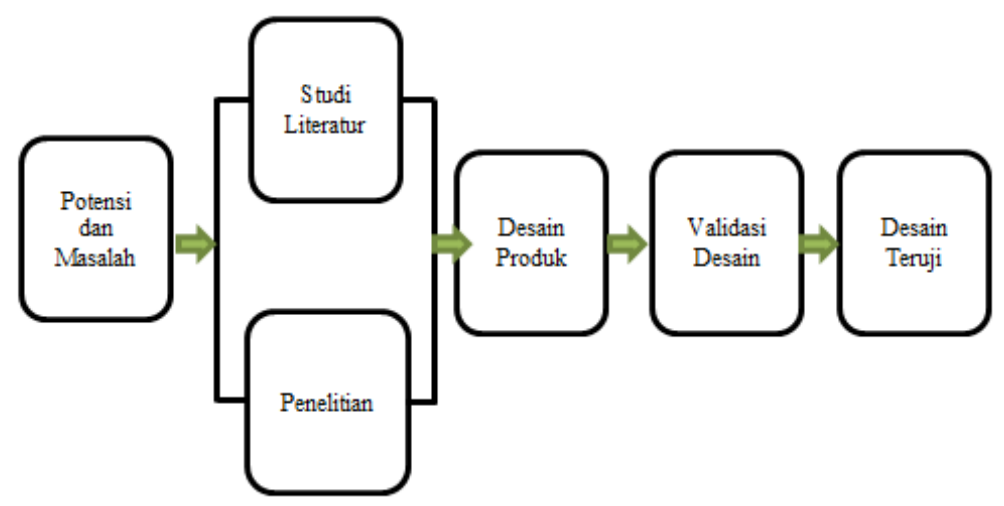

Gambar. 1 Prosedur penelitian dan pengembangan

(Sumber: Sugiyono, 2016)

Sumber data dalam penelitian ini adalah akademisi pemerhati green building, praktisi GBCI, ahli arsitektur, ahli energi dan ahli perangkat pembelajaran. Data yang didapatkan dari hasil penelitian dianalisis secara kuantitatif dan kualitatif. Hasil angket dari ahli dan siswa dianalisis secara kuantitatif, sedangkan hasil wawancara, dokumentasi dan observasi hanya dianalisis secara kualitatif.

\section{HASIL PENELITIAN DAN PEMBAHASAN}

Media maket didesain sebagai alat bantu pembelajaran. Maket sebagai alat bantu dalam pembelajaran lebih ditekankan untuk mempermudah siswa memahami dan untuk mengingat kembali materi yang disajikan dalam maket. Media ini juga dapat digunakan dosen pada saat kegiatan belajar mengajar. Hasil penelitian media maket sebagai media pembelajaran pada mata kuliah konstruksi bangunan gedung dibagi menjadi 3 tahapan yaitu:

\section{Tahap Studi Pendahuluan}

Studi pendahuluan yang dilakukan berupa studi literatur atau studi pustaka merupakan kajian untuk mempelajari konsep-konsep atau teori-teori yang berkenaan tentang rumah ramah lingkungan dan Greenship Homes dari Green Building Council Indonesia (GBCI) terkait kriteria yang disyaratkan. Pada tahap ini didapatkan sebuah ide atau gagasan yang berupa penerapan dari kriteria Greenship Homes dari Green Building Council Indonesia $(G B C I)$ yang menghasilakan sebuah konsep. Materi-materi mata kuliah Konstruksi Bangunan Gedung didapat dari sumber bahan ajar perkuliahan. Hasil studi literatur dapat dilihat pada pemenuhan kriteria Greenship Homes dari Green Building Council Indonesia (GBCI) dan sumber belajar silabus dan rencana pembelajaran semester (RPS) mata kuliah Konstruksi Bangunan Gedung. 


\section{Tahap Perancangan}

Perancangan desain merupakan tahap penting dalam perancangan desain konservasi dan efisiensi energi pada rumah lingkungan sebagai media pembelajaran. Pada proses pembuatan desain dilakukan pada tanggal 2 Februari-31 Maret 2017 di lingkungan Laboratorium PTB FKIP UNS dengan menggambar langsung denah rumah, penentuan jumlah titik lampu, penentuan letak titik lampu, penggambaran instalasi listrik dan penggambaran instalasi panel surya.

Langkah-langkah perancangan desain konservasi dan efisiensi energi pada rumah sederhana antaralain:

a. Menentukan konsep rumah

b. Membuat denah

c. Menghitung jumlah titik lampu

Menentukan jumlah titik lampu dengan pedoman SNI 03-6197-2000 dimana terdapat standar lux yang dibutuhkan setiap ruangnya, adalah sebagai berikut:

Total Lumen $=$ Lux $x$ Luas Ruang

Jumlah lampu $=\frac{\text { Total Lumen }}{\text { Lumen pada lampu }}$

(Lumen pada lampu diketahui pada kemasan lampu).

\section{d. Meteran Listrik}

Dalam rumah ada meteran listrik baik dari listrik jaringan dan jaringan listrik swadaya. Ini dimaksudkan untuk mengetahui konsumsi energi listik agar dapat melakukan pemantauan dan penghematan energi listrik.

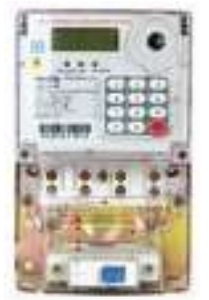

Gambar 2. Meteran Listrik

(Sumber: hematlistrik.blogspot.com diakses pada 15 Maret 2017)

e. Analisis Desain Pasif

Dilakukan untuk meningkatkan pemahaman konsep desain pasif sebagai upaya untuk mengurangi konsumsi energi.

\section{f. Sub Meteran (Sub Metering)}

Menurut Many Fernandez (2015: 15) sub meteran adalah program sub meteran ini dimaksudkan untuk membantu menghemat energi, yang merupakan sesuatu yang kita tetap berkomitmen. Konservasi dan efisiensi energi pada rumah dapat dilakukan dengan upaya menyediakan sub metering untuk salah satu komponen: lampu atau AC atau kontak-kontak listrik. Melakukan perhitungan konsumsi listrik pada rumah $\left(\mathrm{kwh} / \mathrm{m}^{2}\right)$. Memasang Sub metering yang bertujuan agar penggunaan sumber daya lebih terpantau dan memudahkan dalam penghitungan konsumsi sumber daya.

g. Pencahayaan Buatan (Artificial Lighting) 
Penghematan dapat diperoleh dari pencahayaan buatan. Menggunakan lampu dengan penggunaan daya listrik lebih hemat sebesar 30\%, daripada besar penggunaan listrik (daya pencahayaan) yang tercantum dalam SNI $036197-$ 2011. Menggunakan LED sebagai pencahayaan di dalam rumah diharapkan mampu mengurangi konsumsi daya listrik. Perlu adanya zonasi pencahayaan untuk ruang keluarga dan ruang makan di rumah yang menyesuaikan dengan aktifitas penghuni rumah. Menggunakan fitur otomatisasi seperti sensor gerak, timer, atau sensor cahaya minimal pada satu area ruangan rumah.

h. Pengkondisian Udara (Thermal Condition)

Menghemat penggunaan dari perencanaan AC sesuai kebutuhan. Rumah mampu memberikan kondisi termal yang nyaman bagi penghuni tanpa menggunakan $\mathrm{AC}$ dan telah memenuhi minimal 3 poin dari IHC (Indoor Health and Comfort).

i. Reduksi Panas (Heat Reduction) Mengurangi panas rumah yang diterima rumah dari selubung rumah. Adanya upaya desain dan atau penggunaan bahan bangunan yang dapat mereduksi panas pada seluruh atap (tidak termasuk skylight). Pada pemilihan desain maupun penggunaan bahan bangunan dapat mengacu pada SNI 03-6389-2000 untuk nilai radiasi dinding luar dan atap tak tembus cahaya. Adanya upaya desain dan atau penggunaan bahan bangunan yang dapat mereduksi panas pada seluruh dinding dan lantai. Selain adanya upaya desain maupun pernggunaan bahan bangunan yang dapat mereduksi panas pada dinding luar dan atap, perlu juga adanya upaya desain untuk mereduksi panas pada seluruh dinding maupun lantai hal ini dilakukan sesuai dengan SNI 03-6389-2000. Upaya reduksi panas yang digunakan dalam penelitian ini adalah dengan penggunaan material onduline bitumen sebagai penutup atap dan keramik lantai sebagai penutup lantai.

j. Piranti Rumah Tangga Hemat Energi (Energy Saving Homes Appliances)

Mendorong penggunaan peralatan elektrik yang hemat Menggunakan peralatan elektrik pada rumah yang berlabel hemat listrik minium sebanyak $75 \%$ dari total daya (watt) peralatan elektrik.

k. Sumber Energi Terbarukan (Renewable Energy Source)

Rumah ramah lingkungan diharapkan memiliki fitur pembangkit listrik alternatif, ini bertujuan agar adanya 
pengurangan penggunaan dari sumber pembangkit listrik yang berasal dari fosil non terbarukan. Pembangkit listrik alternatif yang digunakan rumah tinggal ialah, panel surya. Pada desain bangunan ini menggunakan panel surya seluas 11 $\mathrm{m}^{2}$ dengan produksi daya listrik 5 $\mathrm{kWh} /$ perhari.

Media pembelajaran yang telah tersusun selanjutnya divalidasi oleh ahli materi dari bidang kajian konstruksi bangunan gedung, ahli pembelajaran, serta ahli media. Hasil penelaahan para ahli sebagai data kuantitatif dituangkan dalam instrumen daftar cek dengan skala rating (rating scale).

\section{Validasi Ahli Materi}

Validasi materi dilakukan oleh validator ahli materi. Validator ini adalah ahli yang mempunyai latar belakang pendidikan di bidang instrumen dan perangkat pembelajaran, mempunyai gelar akademis minimal magister.

Penilaian ahli materi terhadap media pembelajaran yang sudah dibuat diukur dengan 3 aspek, yaitu aspek kelayakan isi materi, aspek sistematika penyajian, dan aspek kelengakapan penyajian yang masing-masing pertanyaan memiliki skor 1-5.

Hasil penelaahan para ahli materi disajikan sebagai data kuantitatif dan rangkuman hasil validasi 2 ahli materi dapat dilihat pada Tabel 1.

Tabel 1 Rangkuman Validasi Ahli Materi

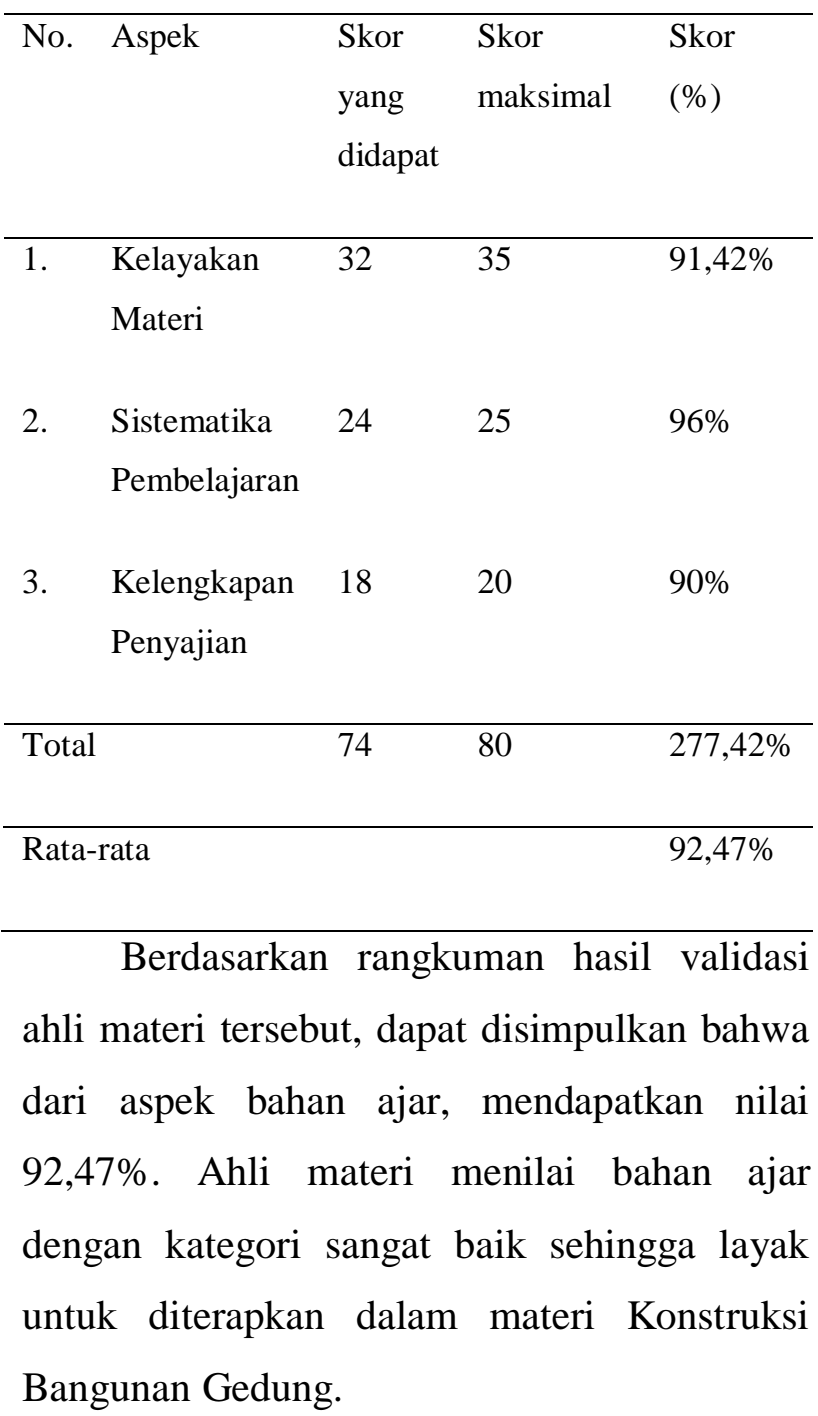

Berdasarkan rangkuman hasil validasi ahli materi tersebut, dapat disimpulkan bahwa dari aspek bahan ajar, mendapatkan nilai 92,47\%. Ahli materi menilai bahan ajar dengan kategori sangat baik sehingga layak untuk diterapkan dalam materi Konstruksi Bangunan Gedung.

\section{Validasi Ahli Pembelajaran}

Validasi pembelajaran dilakukan oleh validator ahli pembelajaran. Validator ini adalah ahli yang mempunyai latar belakang pendidikan di bidang instrumen dan perangkat pembelajaran, mempunyai gelar akademis minimal magister.

Penilaian ahli pembelajaran terhadap media pembelajaran yang sudah dibuat diukur dengan 5 aspek, yaitu aspek perumusan tujuan pembelajaran, aspek pemilihan dan pengorganisasian materi ajar, pemilihan sumber belajar/media pembelajaran, 
skenario/kegiatan pembelajaran dan penelitian hasil belajar yang masing-masing pertanyaan memiliki skor nilai 1-5.

Hasil penelaahan para ahli pembelajaran disajikan sebagai data kuantitatif dan rangkuman hasil validasi 2 ahli pembelajaran dapat dilihat pada Tabel 2.

Tabel 2 Rangkuman Validasi Ahli Pembelajaran

\begin{tabular}{|c|c|c|c|c|}
\hline No. & Aspek & $\begin{array}{l}\text { Skor yang } \\
\text { didapat }\end{array}$ & $\begin{array}{l}\text { Skor } \\
\text { maksimal }\end{array}$ & $\begin{array}{l}\text { Skor } \\
(\%)\end{array}$ \\
\hline 1. & $\begin{array}{l}\text { Perumusan tujuan } \\
\text { pembelajaran }\end{array}$ & 14 & 15 & $93,33 \%$ \\
\hline 2. & $\begin{array}{l}\text { Pemilihan dasar } \\
\text { pengorganisasian } \\
\text { materi ajar }\end{array}$ & 19 & 20 & $95 \%$ \\
\hline 3. & $\begin{array}{l}\text { Pemilihan sumber } \\
\text { belajar/media } \\
\text { pembelajaran }\end{array}$ & 13 & 15 & $86,67 \%$ \\
\hline 4. & $\begin{array}{l}\text { Skenario/kegiatan } \\
\text { pembelajaran }\end{array}$ & 18 & 20 & $90 \%$ \\
\hline 5. & $\begin{array}{l}\text { Penelitian hasil } \\
\text { belajar }\end{array}$ & 14 & 15 & $93,33 \%$ \\
\hline Total & & 78 & 85 & $458,3 \%$ \\
\hline Rata-1 & & & & $91,66 \%$ \\
\hline
\end{tabular}

Berdasarkan rangkuman hasil validasi ahli pembelajaran tersebut, dapat disimpulkan bahwa dari aspek RPP, mendapatkan nilai 91,66\%. Ahli pembelajaran menilai RPP dengan kategori sangat baik sehingga layak untuk diterapkan dalam pembelajaran Konstruksi Bangunan Gedung.

\section{Validasi Ahli Media}

Validasi media dilakukan oleh validator ahli media. Validator ini adalah ahli yang mempunyai latar belakang pendidikan di bidang instrumen dan perangkat pembelajaran, mempunyai gelar akademis minimal magister.

Penilaian ahli media terhadap media pembelajaran yang sudah dibuat diukur dengan 2 aspek, yaitu aspek desain pembelajaran dan aspek Desain komunikasi visual yang masing-masing pertanyaan memiliki skor 1-5.

Hasil penelaahan para ahli media disajikan sebagai data kuantitatif, dan rangkuman hasil validasi 2 ahli media dapat dilihat pada Tabel 3.

Tabel 3 Rangkuman Validasi Ahli Media

\begin{tabular}{lllll}
\hline No. Aspek & $\begin{array}{l}\text { Skor } \\
\text { yang } \\
\text { diperoleh }\end{array}$ & $\begin{array}{l}\text { Skor } \\
\text { maksimal }\end{array}$ & $\begin{array}{l}\text { Skor } \\
(\%)\end{array}$ \\
& & & & \\
\hline $1 . \quad \begin{array}{l}\text { Desain } \\
\text { Pembelajaran }\end{array}$ & 36 & 40 & $90 \%$ \\
& & & \\
2. $\quad \begin{array}{l}\text { Komunikasi } \\
\quad \text { Visual }\end{array}$ & 46 & 50 & $92 \%$ \\
& & & \\
\hline Total & 82 & 90 & $182 \%$ \\
\hline Rata-rata & & & $91 \%$
\end{tabular}

Berdasarkan rangkuman hasil validasi ahli media tersebut, dapat disimpulkan bahwa dari aspek media, mendapatkan nilai $91 \%$. Ahli media menilai media dengan kategori sangat baik sehingga layak untuk diterapkan 
dalam pembelajaran Konstruksi Bangunan Gedung.

Berdasarkan hasil gambar desain yang telah diuji validasi oleh para ahli dan praktisi, kemudian gambar desain divisualkan dalam bentuk maket. Bahan yang digunakan pada maket adalah Polyvinyl Chloride (PVC) dan acrylyc. Skala yang digunakan pada maket adalah 1:25.

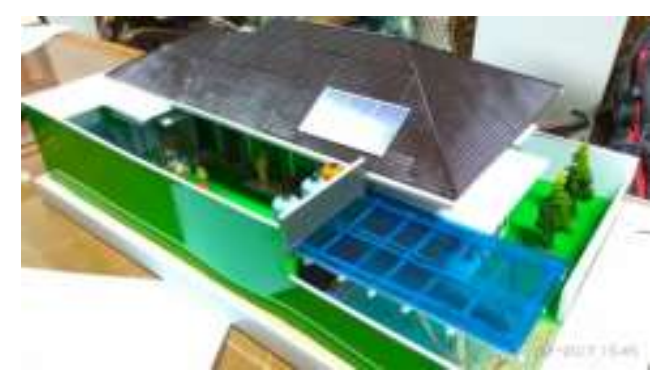

Gambar Maket PVC

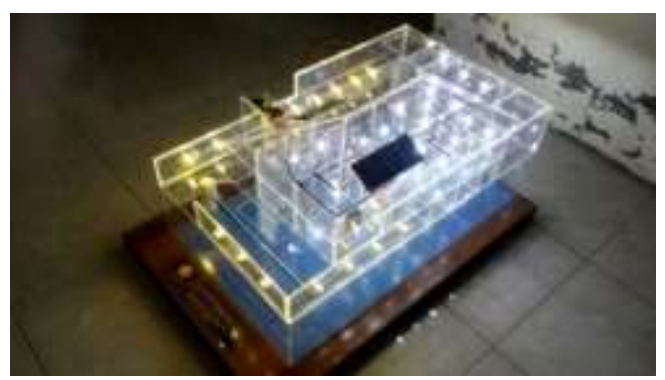

Gambar Maket Acrylyc

\section{Tahap Finalisasi Produk}

Dalam tahap ini, produk telah divalidasi oleh ahli yang berupa model teruji. Hasil akhir ini berupa produk yang memenuhi standar pengujian oleh ahli sebagai media pembelajaran.

Berdasarkan proses pengujian yang telah dilakukan produk dapat sangat layak digunakan dalam pembelajaran konstruksi bangunan gedung. Hal ini didukung dengan adanya Rencana Pelaksanaan Pembelajaran (RPP) materi konservasi dan efisiensi energi pada rumah ramah lingkungan mata kuliah konstruksi bangunan gedung.

\section{KESIMPULAN DAN SARAN}

Media pembelajaran yang dihasilkan dari penelitian ini dibuat berdasarkan desain konservasi dan efisiensi energi untuk rumah ramah lingkungan dengan 8 kriteria dan tolak ukur yang harus dipenuhi, yakni: meteran listrik (electricity meteering), analisis desain pasif (passive design analysis), sub meteran (sub meteering), pencahyaan buatan (artificial lightning), pengkondisian udara (thermal condition), reduksi panas (heat reduction), piranti rumah tangga hemat energi (energy saving homes appliances) dan sumber energi terbarukan (renewable energy source). Sangat penting untuk dianalisa sebagai acuan, agar konsep konservasi dan efisiensi energi pada rumah ramah lingkungan terpenuhi.

Perancangan desain konservasi dan efisiensi energi pada rumah ramah lingkungan rating platinum menurut Greenship Homes dari Green Building Council Indonesia $(G B C I)$, meliputi beberapa tahap, antaralain: (1) tahap studi pendahuluan (2) tahap studi perancangan (3) tahap finalisasi produk.

Berdasarkan penilaian dari validator diperoleh hasil bahwa ahli materi menilai media ini termasuk dalam kategori sangat 
baik, ahli pembelajaran menilai media ini termasuk dalam kategori sangat baik, ahli media menilai media ini termasuk dalam kategori sangat baik.

Berdasarkan hasil penelitian ini, dapat dikemukakan beberapa saran yaitu agar maket konservasi dan efisiensi energi pada rumah ramah lingkungan menjadi referensi para pendidik, untuk mengembangkan media pembelajaran yang memuat materi ramah lingkungann untuk meningkatkan pemahaman mahasiswa akan mata kuliah konstruksi bangunan gedung.

\section{DAFTAR PUSTAKA}

Dina Indriana. 2011. Ragam Alat Bantu Media Pengajaran. Yogjakarta: Diva Press.

Kementrian Energi dan Sumber Daya Mineral. 2012. Buku Pedoman Energi Efisiensi untuk Desain Bangunan Gedung di Indonesia. Jakarta: Direktorat Jenderal Energi Baru, Terbarukan dan Konservasi Energi, Kementerian Energi dan Sumber Daya Mineral Indonesia.
Maulana D.J, Heri. 2009. Teknik Menggambar Mode Busana. Yogyakarta: Kanisius.

Park, Hye Sook, Park, Kyoo Hong. 2001. Analysis of the Mathematical Dispotition of the Mathematically Gifted Students in the MidlleSchool of Korea. Seowon University Cheongju, Chungbuk 361-742, Korea. Journal

Simamora S, Raymond. 2009. Buku Ajar Pendidikan dalam Keperawatan. Jakarta: EGC.

Subkiman, Anwar, Dwinita Larasati dan Budi Isdianto. 2014. Pemanfaatan Pencahayaan Siang pada Interior Gedung Kampus PT Dahana sebagai Strategi Penerapan Prinsip Bangunan Berkelanjutan. Itenas Rekayasa, II, 2, PP. 64.

Sudjana, N dan Rivai (2007) dalam kutipan

Prasotowo. 2010. Media Pengajaran.

Bandung: Sinar Baru Algesindo.

Sugiyono. 2016. Metode Penelitian dan

Pengembangan Research and

Development. Bandung: PT. Alfabeta.

Wonohardjo, Surjamanto. 2009. Skema Konservasi Energi Melalui Sektor Rumah Tangga dan Bangunan. Bandung: ITB press. 